Portland State University

PDXScholar

7-24-1975

\title{
Articulation Error Rates for Oral Reading Tasks in Children with Developmental Apraxia of Speech
}

Kenneth Jerry Arkell

Portland State University

Follow this and additional works at: https://pdxscholar.library.pdx.edu/open_access_etds

Part of the Speech Pathology and Audiology Commons

Let us know how access to this document benefits you.

\section{Recommended Citation}

Arkell, Kenneth Jerry, "Articulation Error Rates for Oral Reading Tasks in Children with Developmental Apraxia of Speech" (1975). Dissertations and Theses. Paper 2267.

https://doi.org/10.15760/etd.2264

This Thesis is brought to you for free and open access. It has been accepted for inclusion in Dissertations and Theses by an authorized administrator of PDXScholar. Please contact us if we can make this document more accessible: pdxscholar@pdx.edu. 
AN ABSTRACP OF THE THESIS OF Kenneth Jerry Arkell for the Master of Science in Speech Communications Emphas is in Speech Pathology/ Aud1ology presented July 24, 1975.

Title: Articulation Error Rates for Oral Reading Tasks in Children with Developmental Apraxia of Speech

APPROVED BY MEMBERS OF THE THESIS COMMITTEE:

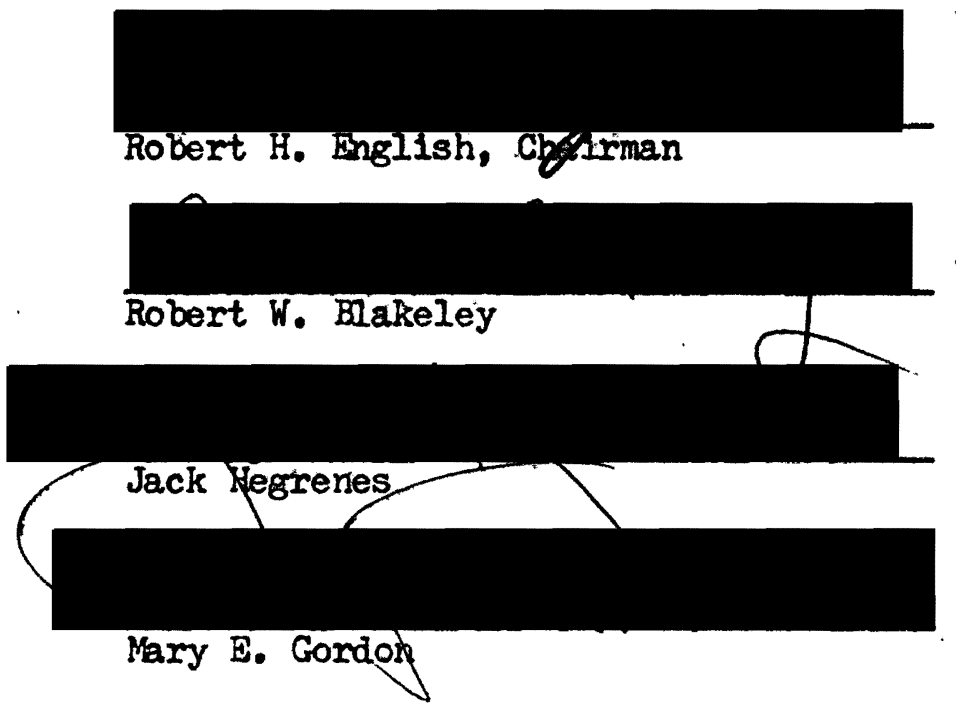

Recently, there have appeared in the literature treatment approaches for the disorder of developmental apraxia of speech in children. These treatment approaches make use of the visual modality, and specifically use reading stimulus materials to improve articulation skills. Several authors have endorsed this use of reading materials in the treatment of developnental apraxia of speech in children including: Morley (1965); Rosenthal (1971); Rosenbek and Wertz (1972); and Rosenbek et al. (1974). These treatment approaches 
have been offered via the Iiterature without the benefit of empirical verification that children with DAS will make fewer articulation errors while reading aloud than they would speaking spontaneously.

The primary purpose of this investigation was to provide empirical support for the treatment approaches to DAS in children which make use of reading stimuli to improve the articulation performance of these children. A secondary purpose was to present a possible treatment approach through the increasing of oral reading speed in children with DAS. Two specific null hypotheses were posed in this study :

1. Children diagnosed as having developmental apraxia of speech will not make significantly more articulation errors on an oral reading task than they do on a spontaneous speaking task.

2. Children diagnosed as having a developmental apraxia of speech will not make significantly. more articulation errors on an oral reading task when reading at their normal rate, than when instructed to perform that oral reading task as fast as possible.

Six children with DAS were chosen from the files of the Crippled Children's Division, University of Oregon Health Sciences Center. These children were screened for concommitant visual problems, hearing problems; organic disabilities, and symbolic language disabilities. Six children from the Canby Public Schools, Canby, Oregon, all having normal articulation skills, served as the control group. Each subject was instructed to read several paragraphs aloud at his/her normal rate. Then the subject was instructed to describe in his/her own words, several pictures. Finally, the subject was instructed to read the same paragraphs over, this time as fast as possible. Comparisons of the scores for the spontaneous speaking task and the oral reading at 
normal rate task were made in addition to comparisons between the scores for the oral reading at normal rate task and the reading at fast rate task.

Analysis of the data via the Mann Whitney-U Test produced the following results:

1. No significant difference was found in the articulation error rates of the spontaneous speaking task and the oral reading at normal rate task, for either the experimental or the control group.

2. No significant difference was found in the articulation error rates of the oral reading at normal rate task and the oral reading at fast rate task, for either the experimental group or the control group.

In conclusion, results of the present investigation do not tend to support the current treatment approaches appearing in the ilterature which make use of written stimulus materials to improve articulation skills of children with DAS. The results also do not support the possible treatment procedure offered involving increasing the oral reading speed to demonstrate improved articulation performance. The conclusions reached by this investigation must be tempered by the small sample size used in this study. 
ARTICULATION ERROR RATES FOR ORAI READING

TASKS IN CHTHDEN WITH DEVELOPMENTAI

APRAXIA OF SPEECH

by

KENIETH JERRY ARKELL

A thesis subnitted in partial fulfillment of the requirements for the degree of

HIASTER OF SCIENCE

in

SPEECH CONIUNICATIONS: EMPHASIS IN SPEECH PATHOLOGY/AUDIOLOGY

Portland State UnIversity

1975 
TO THE OFFICE OF GRADUATE STUDIES AND RESEARCH:

The members of the Committee approve the thesis of Kenneth Jerry Arkell presented July 24, 1975.

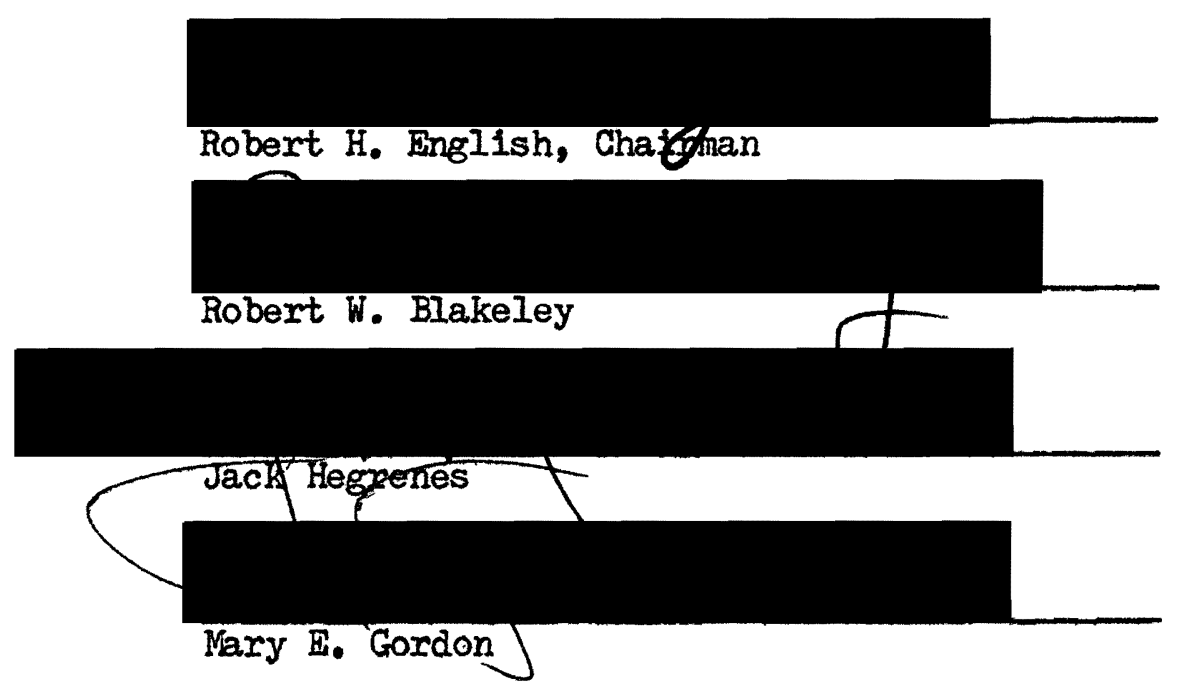

\section{APPROVED:}

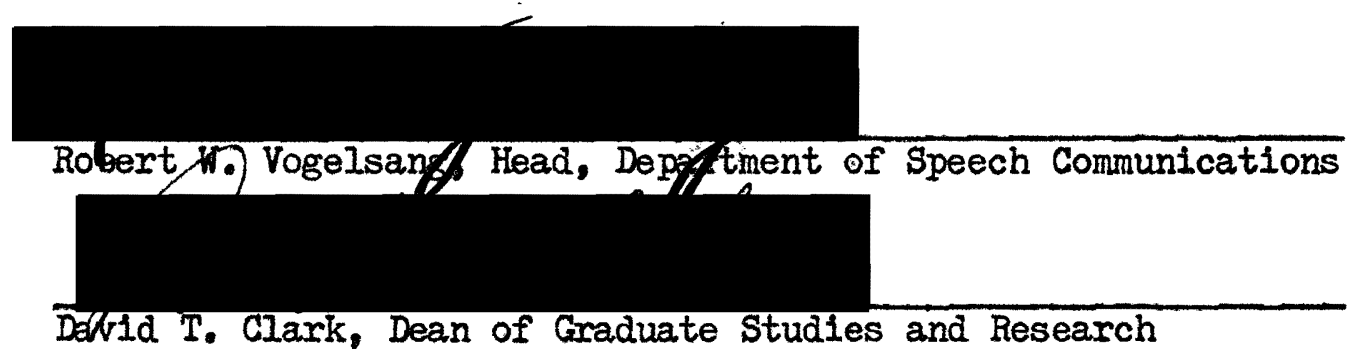

August 1, 1975 


\section{ACKNOWLEDGEMENTS}

I would Iike to thank Dr. Robert English, my advisor and chairman, for all the assistance and time which he spent with me in rewriting and revising my thesis. His critical evaluations of my writing style have improved my writing considerably.

Robert W. Blakeley, Ph.D., of the University of Oregon Health Sciences Center, provided critical assessment and advice concerning the design of this thesis. He always had an open.ear and time to discuss the thesis and the field of Speech Pathology in general.

Mary E. Gordon provided critical evaluation of my writing and thesis format. For this assistance, and for her ability to supervise and develop my clinlcal skills, without molding my personality, I am grateful.

I also would like to thank Jack Hegrenes, Ph.D., of Fortland State's School of Social Work, for his guidance of my statistical analysis. His aid and explanations of statistical theories helped me immensely. 
TABI,E OF CONTENTS

PAGE

ACKNOWLEDGEMENTS . . . . . . . . . . . . . . . 1ii LIST OF TABLES ......................... vii

\section{CHAPTER}

I INTRODUCTION AND STATEIENT OF PURPOSE . . . . . . 1

Statement of Purpose. . . . . . . . . . 2

Definitions ................. 4 Apraxia .

Acquired Apraxia of Speech (AAS)

Developmental Apraxia of Speech (DAS)

II REVIEW OF THE IITERATURE. . . . . . . . . . . History of the Disorder . . . . . . . . . 6 Acquired Apraxia of Speech. . . . . . . . 8 Developmental Apraxia of Speech . . . . . . 10 Treatment . . . . . . . . . . . 15 Summary ................. 19

III IETHODS AND PROCEDURES. . . . . . . . . . . 20 General Plan ............ 20 Subjects .............. 20 Heasurement Instruments . . . . . . . . 22 The Wide Range Achievement Test for Reading

Oral Reading Task 


\section{Pictures}

Peabody Plcture Vocabulary Test - Form B

Photo Articulation Test

Test Setting. . . . . . . . . . . 24

Testing Procedures............. 24

Scoring Procedures. . . . . . . . . 25

Analysis of Results . . . . . . . . 25

IV RESULTS AND DISCUSSION OF RESULTS . . . . . . . . 27

Presentation of Results . . . . . . . . . 27

Total Group Results

Comparison One: Spontaneous Speaking Task

To Oral Reading At Normal Rate Task

Comparison Two: Oral Reading At Normal

Rate Task To Oral Reading At Fast Rate Task

Comparison Three: Control Group To

Experimental Group On All Three Tasks

Discussion of Results . . . . . . . . 32

V SUMIMARY AND IMPLICATIONS. • . . . . . . . 39

Summary . . . . . . . . . . . . 39

Implications. . . . . . . . . . . 41

REFERENCES CITED . . . . . . . . . . . . . . 43

APPENDIX A. Behavioral Characteristics of Apraxic-like

Speech. . . . . . . . . . . 48

APEENDIX B. Bohavioral Characteristics of Developmental

Apraxia of Speech . . . . . . . . 52

APPENDIK C. List of Descriptive Diagnostic Statements

Rank Ordered by Three Speech Pathologists . . . 56

APPENDIX D. Sample of Oral Reading Task . . . . . . . 5? 
PAGE

APrENDIX E. Formula for Computine Nann Whitney-U Test . . . 58 APHEINDIX F. Age and Sex of All Subjects Participating.

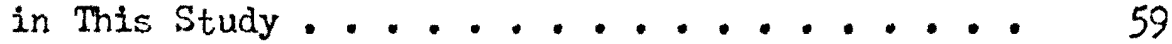




\section{IIST OF TABLES}

TABLE

PAGE

I Composite of Individual Scores On All Tasks . . . . .

II The p-Values For The Experimental Group And

Control Group Comparing Tasks Performed

By Each Group ............. 30

III The p-Values For Each Task Comparing The

Control And Experimental Groups'

Articulation Error Rate . . . . . . . . : 
differentially diagnosed early in Iife or in the school systems as to the nature of their problem (Fay, 1974; Ferry et al. 1974). These children also do not appear to be responsive to the type of traditional articulation treatment offered today (Yoss, 1973). The diagnostic entity, developmental apraxia of speech is relatively young and successful treatment procedures for this disorder are even younger. Indeed, successful treatment programs reported in the literature are scarce. Those treatment approaches that do exist often have been the result of single case studies, or the reports of a child's failure to respond to a given treatment approach. Recently, reports of successful treatinent approaches, however, have begun to appear in the literature. In these treatment programs, the use of reading stimulus materials has played a significant role.

Rationale and empirical support for the use of reading stimul1 has not been forthcoming in the 1iterature. In fact, there appears to be considerable inconsistency and contradiction concerning reading skills in children who have a developmental apraxia of speech. The speech clinician working with this disorder is left with a treatment approach for which there seems to be no emplrical support of its rationale.

\section{Statement of Furpose}

The purpose of the present investigation was to provide support for the treatment approaches which involve the use of reading stimulus materials in order to correct articulation errors of children diagnosed as having developmental apraxla of speech. Additionally, a secondary 
purpose of this investigation was to explore the possibility of Improving articulatory performance of children diagnosed as having developmental apraxia of speech by instructing them to increase their oral reading speed.

In designing this study, certain basic assumptions were made, These assumptions were: 1) Children diagnosed as having developmental apraxia of speech make significantly more articulation errors on oral reading tasks than children with normal articulation skills; and 2) Children diagnosed as having developmental apraxia of speech make significantly more articulation errors on spontaneous speaking tasks than children with normal articulation skills. The validity of these assumptions will be discussed in Chapter IV.

For the convenience of the present investigation, the following null-hypotheses were formulated in order to facilitate the analysis of data.

1. Children diagnosed as having developmental apraxia of speech will not make significantly more errors on an oral reading task than they do on a spontaneous speaking task.

2. Children diagnosed as having developmental apraxia of speech will not make significantly more articulation errors on an oral reading task when reading at their normal rate, than when instructed to perform that oral reading task as fast as possible.

Implied in the rejection of null-hypotheses is the possible acceptance of alternative hypotheses, (Siegel, 1956). The alternative hypotheses offered in this investigation are:

1. Children diagnosed as having developmental apraxia of speech will make significantly fewer articulation errors on an oral reading task, than they do on a spontaneous speaking task. 
2. Children diagnosed as having developmental apraxia of speech will make significantly fewer articulation errors on an oral reading task when instructed to perform that task as fast as possible than when instructed to perform that oral reading task at their normal rate.

\section{Definitions}

Literature relating to the area of apraxia recognizes and uses the terms apraxia (Darley, 1968, 1970) and dyspraxia (Edwards, 1973) to describe the same disorier. This does not appear to mean, in the cases diagnosed as apraxic, a total inability to articulate speech exists. This study will follow the precedent set by the majority of sources cited in this study and define any degree of apraxic/dyspraxic condition to be apraxia rather than dyspraxia.

For the purposes of this study the following operational definitions will be utilized. Additionally, Appendix A provides a rather complete list of the specific speech behaviors associated with apraxia of speech.

\section{Apraxia}

The term apraxia is defired by Taber's Cyclopedic Medical Dictionary $(1970$, p. A-82) as an ". . Inability to perform certain purposive movements without loss of motor power, sensation, or coordination..." This condition can affect all or any part of the body which moves volitionally, including the gross musculature as well as the fine muscles of the body. Apraxia is the generic term from which dovelopmental apraxia of speech as well as acquired apraxia of speech are dexived. Also the term apraxia is associated with both 
children and adults.

Acquired Apraxia of Speech (AAS)

AAS is the abbreviation which will be used in the present study for the term acquired apraxia of speech. This term may be defined as a condition in which, 1) the person cannot volitionally articulate speech correctly; 2) there is an absence of paralysis or paresis in the speech musculature; 3) all oral structures are Intact; and

4) there is a known etlological reason for this condition. AAS may be found in children as well as adults, although it is usually reported In the I1terature in connection with adults.

Developmental Apraxla of Speech (DAS)

For the purposes of this study, DAS is the abbreviation which will be used for the term developmental apraxia of speech. It is defined as a condition in which: 1) the person cannot volitionally articulate speech correctly; 2) in which there is an absence of paralysis or paresis in the speech musculature; 3) all oral structures are intact; and 4) there is no known etiological reason for this condition. DAS is found in adults only if it was present from birth, however, it is usually associated with children in the I1terature. 
CHAPTER II

REVIEW OF THE IITERATURE

\section{History of the Disorder}

Apraxia of speech has been known and described for at least 114 years. According to Darley (1968), Broca first described the disorder In 1861. Since that time, the disorder has been reported in the journals and as Yoss (1972a, p. 9) has stated: ". . the clintcal condition has indeed been consistent; it is the terminology applied that has been so varled and confusing ..." This proliferation of terms which has appeared in the Iiterature has included aphemia, Broca's aphasia, expressive aphasia, verbal aphasia, motor paraphasia, phonemic paraphasia, apraxic dysarthria, dyspraxic dysarthria, cortical dysarthria, anarthria, phonetlc disintegration of speech, verbal apraxia, articulatory apraxia, and apraxia of speech. The intent of this section is not to cover every major contributor nor to provide an in-depth history of this disorder. It will attempt, instead, to point out this prollferation of terms or "labels" generated in the last 114 years.

Hughlings Jackson in 1866, described a patient as having the inabilities necessary to perform volitional acts with his tongue and Ilps although the muscles were intact (Darley, 1968). In 1900, Liepmann was the first to call the behaviors described by Jackson apraxia. According to Derley (1968), Liepmann stressed a lack of 
volitional control and intact muscle strength. Ceschwind (1975) has also credited Ilepmann with great insight into possible areas of the brain in which the dysfunction or damage causing the apraxia may exist. The Iink between aphasia and apraxia was reinforced when Henry Head used the term "verbal aphasia" to describe what he personally felt was a form of apraxia (Darley, 1968). Alajouantne, Ombredane, and Dirand added to the dichotomous confusion by writing a book titled The Syndrome of Phonetic Disintegration in Aphasia (as reported in Darley, 1968). The close link with aphasia continued when in 1948 Goldstein improvised the term peripheral motor aphasia (Johns and Darley, 1970). FInally, in 1955, Wepman delineated apraxia from aphasia by stating apraxia did not represent a problem of symbolic formulation but rather a transmissive problem (Darley, 1968). In 1966, Shankweller and Harris reported on the articulatory (once again working with adults) performance of five patients with apraxia of speech. DeRenzi et al.. as reported in Darley (1968), used the term anarthria to describe seventyone patients with apraxia of speech. lany of these patients also had an "oral apraxia." Therefore, a survey of the 11terature reveals three common factors relative to apraxia of speech: 1) it is most commonly found in association with apraxda; 2) it is most frequently found in adults; and 3) it is always found after the patient had acquired his speech and language skills.

It was not until the $1960^{\circ}$ s that apraxia began to be associated with children. Palmer (1964) was one of the first to examine children with functional articulation problems and to find among some of them a eroup of symptoms which he labelled a "Iingual apraxia." The term 
"developmental" was first applied to apraxia of speech by Morley (1965, p. 175); she termed the disorder "developmental articulatory apraxia." Her classic description of the disorder is presented here:

In contrast to those children with developmental dysarthria we find those who apparently have no difficulty in moving the tongue, lips, or palate for spontaneous movements but have difficulty in directing them for voluntary imitation of movements or for the reproduction of the correct articulatory sounds when hearing is normal. In such children the disturbance of function probably originates at a higher level of the nervous system and may be described as an apraxic dysarthria. or articulatory apraxia, or more commonly dyspraxia, according to the degree of severity.

As noted in the foregoing cltations from the literature, the term developmental apraxia of speech refers to a disorder which has evolved from research with adults over the past one hundred years. W1th the passage of time apraxia of speech gradually separated itself from aphasia, and in the last decade the term, developmental apraxia of speech, has been applied to children.

Since 1965, a number of articles have appeared in the literature dealing with apraxia of speech, and the authors of several of these same articles have focused on developmental apraxia of speech. An article written by Darley in 1968 gives a rather complete review of apraxia of speech and its history. Wuch of the foregoing material for this section was obtained from that article.

$$
\text { Acquired Apraxia of Speech }
$$

It would appear that DAS was Identified as a syndrome in children as a result of its similarity to acquired apraxia of speech. Therefore, in this section consideration will be given to the disorder termed an acquired apraxia of speech (AAS). 
In reporting on the largest sample of apraxics found in the Iiterature ( $N=228)$, Wertz et al. (1970) noted that apraxia of speech in adults occurred in isolation only 13 percent of the time. Additionally they observed it appeared in combination with aphasia in 65 percent of the cases, with dysarthria in 8 percent of the cases, and in conjunction with aphasia and dysarthria in 14 percent of the cases. In adults, it would seem, the most common et1ology of AAS is vascular in nature. According to Wertz et al. (1970), their adult population of AAS subjects fell into the following etiological classifications: 68 percent were found to be vascular; neoplastic lesions accounted for 13 percent; trauma 7 percent; and 6 percent were of undetermined origins. Additionally, they noted infectious, miscellaneous etiologies such as epilepsy and Jacob Creutzfeldt disease accounted for more than 1 percent of their population.

There are many clinically observable articulatory behaviors which have been reported in the literature as being characteristic of acquired apraxia of speech. Not all of these characteristic behaviors are consistent throughout the Iiterature; nor are they consistent within each patient. There are, however, several articulatory behaviors which seem to be quite consistent. One of these behaviors is the inconsistent error patterm in articulation (Darley, 1968; Johns and Darley, 1970). Another commonly reported characteristic is the type of phonemic errors made. These errors consist of: omissions, substitutions, distortions, and repetitions (Darley, 1968, Johns and Darley, 1970). A third characteristic behavior is the "trial-anderror" groping by the person with acquired apraxic-like speech trying 
to find the right way to move his articulators to produce the desired speech (Darley, 1968; Johns and Darley, 1970). Awareness of his own articulation errors is also a common characteristic of a person with AAS (Darley, 1968; Johns and Darley, 1970). The prosodic elements of speech are often disturbed also (Johns and Darley, 1970). Finally, in apraxic speech; there are usually some areas of error free speech. These areas are emotive, automatic-reactive speech such as cursing, laughing and singing (Darley, 1970). There are, as previously mentioned, other characteristic articulatory behaviors. Appendix A contains a list of thirteen behaviors characteristic of apraxic-like speech from Darley (1968).

The picture presented here is one of a disorder which occurs as the result of and subsequent to brain damage; it usually occurs in conjunction with aphasia and/or dysarthria. Typical behavioral symtoms of this disorder are: Inconsistent error patterns and types of errors, some areas of speech which are relatively error-free, and an awareness by the patient of his articulation errors. With this description of AAS in mind, it is now appropriate to examine DAS.

\section{DEVELOPYENTAI APRAXIA OF SPEECH}

Developmental apraxia of speech, as stated earlier, has been recognized as a disorder only in the last ten years. The tie between DAS and AAS is very strong. DAS evolved as a recognized diagnostlc entity from research involving persons who had an AAS, which initially resulted from research dealing with aphasia. As one might predict, there are many similarities between the two types of apraxia. In fact, 
the clinical descriptions of the two disorders are so similar only the differences will be considered in this section. See Appendix B for a complete list of the behavioral characteristic speech symptoms of DAS as presented by Rosenbek and Wertz (1971) and Fay (1974).

Prior to looking at the similarities and differences between DAS and AAS, it would be helpful to mention the varying severity factor of this disorder. Generally speaking, the I1terature has reported cases which have been moderate to severe with multiple articulation errors and greatly reduced speech intelligibility for both DAS and AAS. At least one reference (Rosenbek et al., 1974), however, has stated DAS can exist in a relatively mild form with only slight prosodic error and a few articulation errors, such as $/ s /, / 1 /$, and $/ r /$. It would be helpful to view the above mentioned clinical behaviors of DAS and AAS as occurring on a continuum of severity from very mild to very severe. It also would be helpful to remember the literature appears to report those cases at the severe end of this continuum. The children on the more moderate end of the continuum, however, are probably the ones overlooked, and are the ones who appear in the case loads of public school speech clinicians' year-after-year. These are the children who have enough articulation skills to enter school but not enough to be intelligible all of the time.

The most obvious difference between DAS and AAS is the time of etiology. AAS is found in those persons who had normaI speech and language skilis until some degenerative process (lesion, trauma, etc.) interrupted normal central nervous system functioning which then disrupted their normal articulatory skills. DAS, however, implies a 
central nervous system disruption occurring prior to the onset of speech (Rosenbek and Wertz, 1971). In addition, at least 33 percent of all diagnosed cases of DAS report a positive familial history of speech problems (Ferry et al.., 1974). Morley (1965), In her study of 12 children with DAS reported a 50 percent incidence of positive familial historles of speech problems. Ferry et al. (1974) also have reported that the disorder appears to be three times as common in boys as in girls. Wertz et.al. (1970) reported (an intensive neurological evaluation failed to reveal any abnormal findings) in 52 children under 14 years of age who were diagnosed as having an apraxia of speech. This statement agrees with the findings of Rosenbek and Wertz (1971). Wertz et al: (1970) found that unlike the adults in their study, 54 percent of the children displayed an apraxia of speech in isolation. They also found in the children, apraxia and dysarthria occurred together in 33 percent of the cases, and apraxia, aphasia, and dysarthria occurred together in 2 percent of the cases.

Rosenbek and Wertz (1971, pp. 9-11) reported several differences in observable characteristic behaviors between DAS and AAS groups. These differences included:

1. The child (DAS) seems to make more sound and syllable onission errors (than does the adult with AAS).

2. The older children's (DAS) error pattern, especially or imitative speech tasks, had much the flavor of the adult apraxic's (AAS). The younger children's (DAS) performance did not.

3. There is a tendency for apraxic children (DAS), especlally the younger ones, to make errors on vowel sounds.

4. Adult apraxics (AAS), however, present a consistent pattern of prosodic disturbances. . . The apraxic 
child (DAS) does not display this consistency.

5. The apraxic child's (DAS) phonemic errors are inconsistent, but probably not so inconsistent as the apraxic adult's (AAS).

Yoss (1972b), in describing a group of thirty children with articulation problems, found a subgroup which she determined were presenting symptoms of DAS. In this subgroup, she detected several differences between DAS and AAS characteristic behaviors. She found distortions, rather than the substitutions usualiy identified with AAS, were more characteristic of DAS in her children. She also found an accompanying oral apraxia was usually present in the children. Only In the older children did she find the trial and error searching and gropling behavior characteristic of AAS. Finally, Yoss found that multiple features of phonemic production were in error in the group of children.

Awareness of exrors is a characteristic often noted in the I1terature. There appears to be considerable disagreement, however, over this characteristic. Morley (1965) stated the adult apraxics are usually aware of their errors because they previously had normal speech, and she feels the children (with DAS) are not usually aware of their errors. Rosenbek and Wertz (1971) and Ferry et al. (1974) imply the children with DAS are aware of their errors in articulation. Yoss. (1972a) felt awareness was a function of age; the older the child, the more aware he is:

A frequently noted characteristic, non-speech behavior of these children is a syndrome of clumsiness and/or a minor motor coordination difficul.ty (Ferry et al. 1974). Geschwind (1975), however, separates 
motor apraxia from articulatory problems which he feels are not even a true apraxia; and should not be labelled as such. To add to the controversy, Yoss $(1972 a)$ reported the literature frequently mentions an overall clumsiness of children with DAS. Finally, Winitz (1969), after going through many of the major studies linking motor ability and articulation problems, stated the evidence was not strong enough to support a link between clumsiness and articulation problems in children.

An accompanying characteristic of DAS in children is the frequent appearance of concomitant learning disabilities (Yoss, 1972a; Ferry et al., 1974). Foremost among the learning disabilities mentioned is reading. After reviewing the literature, however, it is apparent not everyone has looked at reading from the same viewpolnt. Morley (1965) wrote that some children with DAS also will have reading problems. She Inked the severity of the apraxia to the likelihood of a reading disablifty; the more severe the apraxia, the more likely a reading disability. Orton (1937), as reported in Yoss (1972a), stated there appeared to be a high percentage of articulation problems in children who were poor readers.

The confusion regarding reading is not limited to DAS. Darley (1970), speaking on AAS, noted speaking was the modality affected most, and was significantly more affected than listening, reading, or writing. Another viewpoint has been stated by lartin (1974) who viewed a greater frequency of articulation erxors in oral reading as proof that AAS was not a separate disorder but part of a linguistic disorder (presumably aphasia). Johns and Darley (1970) increased the confusion with 
lhe finding that their population of adult AAS subjects performed better when spontaneously describing a picture than when they read aloud or imitated sentences. They also observed when the adult apraxic subjects read as fast as possible, their articulation and overall intelligibility improved. These latter findings by Johns and Darley (1970) are central to this investigation, and will be expanded upon in the next section. The key issue of note here is that the findings (Johns and Darley, 1970) were based on studies of adults with AAS and there seems to be a general lack of concensus relative to the reading alility in persons with an apraxia of speech, either DAS or AAS.

From the above descriptions of DAS and AAS together with the contrast between the two, it is apparent many inconsistancies exist in the literature regarding some of the clinical behavioral symptoms of both DAS and AAS. Throughout this section, however, familial historles and lack of apparent etiologies in DAS are important. The age factor is also important; the older the child with DAS, the more like AAS are his articulatory behaviors. The awareness of errors, the concomitant abilities (motor and learning), and the actual type of inconsistent errors made, are areas in which DAS is not well understood.

\section{Treatment}

When it is recognized that DAS has been identified as a diagnostic entity only within the past ten years, together with its central nervous system involvement, it becomes relatively apparent.why treatment models for this disorder are lacking. Very little has been written about treatment, and a large part of what has been written is anecdotal, 
single case history reports or disheartening reports of little progress. At the present time, it would appear the prognosis for normal speech in moderate to severe cases of developmental apraxia of speech, even under the best of treatment procedures, is poor.

Recent Iiterature appears to be fairly consistent in reporting traditional articulation treatment methods do not work with DAS. As Yoss and Darley (1974, p. 24) so aptly noted, "A central thread of information, however, appears in case reports that mention speech therapy time is required, usually with minimal improvement . . ." Even after a year of public school speech management, Yoss (1973) found little improvement in a study of fifteen cases of DAS in children. She reported the treatment would generally "bog down" at the level of transition from single words (monosyllabic) to single words (polysyllabic) of increasing length and complexity.

Auditory discrimination skill, at a gross level, does not appear to be a major part of the problem; as Rosenbek and Wertz (1971, p. 14) stated. "The classical reliance on auditory discrimination training is probably a waste of time...." In fact, Aten et al. (1971) have stated apraxia of speech can appear without an auditory component. The reported failure of traditional treatment methodologies geared auditorily has promoted research dealing with treatment techniques utilizing other sensory modalities. Tactile and kinesthetic modes have been Iinked with the auditory mode in ChappelI's (1973) program of audiomotor integration. Rosenbek and Wertz (1972) report auditory-visual stimulation is better than elther auditory or visual alone. 
The idea of combining input modality stimulation, however, is not universally recommended. Edwards (1973) reported many children deteriorate rather than progress if over stimulated, multistimulated, or exposed to an excessive variety of stimulation. Rosenbek et al. (1974) appear to concur with this idea of over stimulation through too many input modalities. In an earlier article, Rosenbek et al. (1973) justifled this reasoning by stating many apraxics have an oral-sensoryperceptual deficit, and a multi-sensory approach would not be appropriate for these individuals.

The visual modality has been mentioned in the ilterature as a treatment possibility in at least two different approaches. The first approach is usually combined with the auditory sense, and the technique is to present highly visible sounds both auditorily and visually to the child. It is important here that the child attend visually to the clinician's face while listening to the clinician's model (Yoss and Darley, 1974). The obvious question to be raised is: what does the child do when articulating the non-visible sounds?

The second approach involves the use of reading printed materials and pictures. Morley (1965) reported improvement in articulation sometimes occurs when the child is learning to read. In discussing AAS in adults, Rosenbek and Wertz (1972) felt reading stimuli were often useful in developing good "visual memory" for correct articulatory production. Rosenthal (1971), as reported by Yoss and Darley (1974), stressed the use of the printed word or letter, and, in fact, based an entire treatment paradigm successfully on reading material. The obvious limitation with this type of treatment is the child must already 
know how to read. If the apraxia is severe, there is a chance the child would learn to read "... using his own defective phonemic patterns, and these will then be increasingly reinforced and stablilized in speech ....(Morley and Fox, 1969, p. 159)"

The findings reported in the foregoing references indicate reading is a possible treatment avenue. Earlier, however, it was noted articulation in oral reading was not as good as that in spontaneous speech of adults (lertin, 1974; and Johns and Darley, 1970). It also was reported earlier that at least one source (Johns and Darley, 1970) had indicated articulation in oral reading skills improved when the adult subjects were instructed to read as fast as possible. This finding appears to be inconsistent with Rosenbek et al. (1974), who favored use of the "judicious pause," and with Yoss and Darley (1974) who favored slowing the rate of utterance in spontaneous specch.

The malin point of the preceding discussion is that while reading is being offered as a treatment method for developmental apraxia of speech, it has been found articulation errors are more frequent and Intelligibility is poorer when the adult apraxic subject (AAS) reads aloud. It has been noted that reading problems often accompany DAS in children. Finally, it is to be observed that by increasing the speed of oral reading, overall intelligibillty of the adult apraxic (AAS) Improves even though the literature indicates the slowing of a subject's rate of speaking tends to aid the treatment process. 
Summary

From the literature, a general picture of inconsistencies and unanswered questions linvolving the clinical manifestations of and treatment approaches to the disurders AAS and DAS has emerged. The Johns and Darley (1970) study involving adult subjects with AAS, provides data which does not support the current emphasis on written materials In treatment approaches to DAS. The data does, however, offer an alternative in the finding that increasing the oral reading speed seems to improve articulation in these adults with AAS. The present study used a similar paradigm to that of Johns and Darley in order to test the hypotheses presented in Chapter I. 
CHAPTER III

IETHODS AND PROCEDURES

General Plan

An oral reading task was administered to each of twelve children. In addition, each child was instructed to spontaneously describe several pictures. Finally, each child was asked to perform the oral reading task again as fast as possible. Six children previously diagnosed as having a developmental apraxia of speech comprised the experimental group, and six children without articulation problems, selected from the public schools of Canby, Oregon, comprised the control group.

Subjects

There were twelve subjects, ranging in age from eight to eleven years inclusively, involved in this study six were children diagnosed as having a developmental apraxia of speech; and. six were children with normal articulation skills.

The six developmentally apraxic children, or experimental group, were selected from the files at the Crippled Children's Division (CCD), University of Oregon Health Sciences Center. For the purposes of this study, a list of descriptive statements used to describe apraxia of speech was complied fron the flies. This list was rank ordered by three Speech Pathologists on the staff at CCD. Five statements were 
picked from the three rank ordered Iists. Each descriptive statement selected haci to be agreed upon by at least two of the three Speech Patholocists as being one of the five most significant descriptive, diagnostic statements (see Appendix C for Iist of diagnostic statements) In addition, significant diagnostic statements were selected from the Iiterature in order to augment the Speech Pathologists' 11st. These statements from the Iiterature were not included in the rank ordered lists. All files of chlldxen diagnosed as having developmental apraxia of speech were then examined and only those having at least three descriptive statements from the two sources combined (top five rank ordered statements and statements from the literature) were elfgible for the inclusion in the study.

Additionally, all subjects selected had to meet the following, general criteria:

1. Hearing acuity of $20 \mathrm{~dB}$ or less, based on a puretone audiometric screening test for the frequencies of 500 , 1000,2000 , and $4000 \mathrm{~Hz}$. A Beltone $10 \mathrm{C}$ portable audiometer was used for this screening.

2. Hental ability within the range of 85 IQ points or ahove, based on recent test results found in the child's school monrds, or The Peabody Plcture Vocabulary TestForm (Dunn, 1965), where such recent results were unavailable.

3. Absence of any visual disability which might be a significant, contributing factor to an articulation or reading: problem, based on information in the child's school records and/or family reports.

4. Absence of any organic disability which might be a ifigificant, contributing factor to an articulation or redding problem, based on information in the school records and/or family reports.

5. Zero articulation errors as measured by the Photo Articulation Test (Pendergast et al. 1965), for all the subjects in the control group. 
6. Rcading level at or above the 2.5 grade level as measured by the Wide Rancre Achlevement Test for Reading. (Justak et a.l. 1965) for all subjects of both the experimental and control groups, was picked to make sure that the oral reading tasks involved in this study were not a test of readine skill but rather a test of articulation sikill.

Measurement Instruments

Measurement instruments used in this investigation are described bolow.

The Wide Range Achievement Test For Reading (WRAT)

The WRAT, (Justak et al., 1965) was adninistered in order to determine a minlmum reading level of middle of second grade year. This level insured that the oral reading task was measuring articulation skill and not reading ability. This test consists of one page of words which are arranged in order of increasing difflculty. The child is to read aloud each word, one at a time. The score or reading level is determined by a basal and celling system.

Oral Reading Tasis

This task consisted of several paragraphs containing one-hundredeleven words. The paragraph tells a story about a red hen and her home. These paragraphs were taken from a diagnostic manual at CCD University of Oregon Health Sclences Center. They are rated at the beginning second grade level (2.1) in terms of reading difficulty. A copy of these paragraphs is presented in Appendix D.

Pictures

The pictures used to ellc1t spontaneous speech were taken from a 
Peabody Language Kit - Level 1 (Dunn, 1965). There are six plctures, each of which depicts an action scene. The scenes include: a fire; an astronaut fighting with an outer spaceman; a boy fighting with a dragon; a lion who is escaping from a cage; a motorcycle accident; a cave with a pair of luminous eyes staring out from the cave.

Peabody Picture Vocabulary Test-Form B (FPVT)

The EFVT-Form B (Dunn, 1965) was administered to each of the subjects. This non-verbal. vocabulary recognition test consists of a book of plates with each plate containing four plctures on a plate. The child is instructed to point to one of the four pictures based on a word given by the examiner. The scoring is based on a basal and celling system. The test produces a vocabulary recognition age level score and an $T$ L

Photo Axt1culation. Test (PAT)

The PAT (Fendergast et al., 1965) was administered to all subjects in the control group. This test is a single word, picture stimulus articulation test with photographs used as stimulus words designed to elicit single word samples of speech sounds in initial, medial, and final positions. Scoring was accomplished on an "all or nothing" basis.. In other words, the subject must correctly articulate all of the target sounds in all the stimulus pictures to be included in the study. 
Test Setting:

All testing was conducted in quiet, well lighted rooms at the Crippled Children's Division, and the Canby Public Schools. The subjects were examined one at a time and distractions were minimal during the examination session. Necessary materials for each test session Included:

1. Tape recordex

2. Portable audiometer

3. Test materials

\section{Testing Procedures}

Each testing session began with the administration of the Peabody Flcture Vocabulary Test, which required approximately ten minutes. This was followed by the administration of the Wide Range Achlevement Test for Reading, which lasted about five minutes. The subject was then administered the hearing screening, which required approximately ten minutes. All control group subjects were also administered a Photo Articulation Test. The subject then was asked to read the second grade level paragraph aloud at his/her normal oral reading rate. The task was followed by the subject describing what he/ske saw happening in the pictures. Flnally, each subject was asked to read the oral reading paragraph again, aloud, as fast as possible. All responses to the descriptive task and the two reading tasks were recorded on the tape recorder, while responses to all the other tasks were recorded by pencil. Each individual session lasted between thirty and forty minutes; : on the average. 


\section{Scoring Procedures}

The Wide Range Achievement Test for Reading, the Peabody Plcture Vocabulary Test, and the Photo Articulation Test were scored according to standardized scoring procedures outlined in their respectlve manuals. The oral responses in the reading tasks and descriptive, spontaneous speaking tasks were recorded on a tape recorder and then scored on an Individual, syllable-by-syllable basis. This meant efther all phonemes in each syllable were articulated correctly or the whole syllable was scored as incorrect. In this study, only the presence of articulation emors and not type were marked. All oral responses, reading and spontaneous speaking tasks, were scored twice in order to determine both the accuracy and consistency of scoring.

\section{Analysis of Results}

The statistical analysis of results of the three tasks in this study will be accomplished through the use of the Mann Whitney-U Test (as reported in Siegel, 1956). This test is a nonparametric test used to determine whether two independent groups of data are significantly different. As Stegel $(1956$, p. 116) has stated, "This (Mann Whitney-U Test) is one of the most powerful of the nonparametric tests. . ." The use of a nonparametric test was required because neither the experimental group nor the control group used in this study was a randomly chosen sample, drawn from the total population of possible subjects.

The Mann whitney-U Test is computed by rank ordering two sets of data, and then fnserting that data into a basic formula. The basic 
formula for computing the Mann Whitney-U Test is presented in Appendix E. In this study, the level of significance was set at .05. Therefore, any $\mathrm{p}$ value larger than .05 indicates that no significant difference exists between the two sets of results. 
CHAPTER IV

RESULTS AID DISCUSSION OF RESULTS

Data obtained from the present investigation were analyzed statistically utilizing the Mann Whitney-U Test, (as reported in Siegel, 1956). "These data will be presented under the "Presentation of Rewults" section below, utllizing the following sub-topieal headings:

1. Total Group Results

2. Comparison One: Spontaneous Speaking Task to Oral Reading at Normal Rate Iask

3. Comparison Two: Oral Reading at Normal Rate Task to Oral Reading at Fast Rate Task

4. Conparison Three: Experimental Group to Control Group in Ail Three Tasks

The second section of the chapter, "Discussion of Results," provides a discussion of the results in the light of certain IImitations of the present study together with factors which might possibly have influenced the outcomes of the investigation. Additionally, the obtained data are compared and inter-related with information from the I1terature.

\section{Presentation of Results}

\section{Total Group Results}

A breakdown by age and sex of all subjects is presented in Appendix F. This Appendix will be helpful in referring to inaividual 
subjects in this study.

Table I lists all subjects and the results of their performances In all three tasks, showing the computed means with standard deviation scores for the means. It is to be noted that the table assigns each task a number; these task numbers will be used in the presentation and discussion of results. Task \#One is the spontaneous speaking task, Task \#Tro is the oral reading at normal rate task, and Task \#Three is the oral reading at fast rate task. The experimental group is quite consistent in its mean articulation error rate for all three tasks, as shown in the mean scores in Table I. It would appear Task \#One produced the most consistent scores in both groups (experimental and control). Task \#Three scores appear to be the least consistent throughout for both groups.

Comparison One: Spontaneous Speaking Task to Oral Reading at Normal Rate Task

The Mann Whitney-U Test was applied to the scores of both the experimental and control groups, for Tasks \#One and \#TWo. In Table II, It is shown that a p-value of .197 was achieved for both the experimental and control groups.

The p-value of .197 indicates that given the two tasks, thëse same scores would result approximately one of every five times they were tested. Since the p-value is higher than the .05 level of significance set for this study, it is very likely that the resultant scores from Task \#One and Task \#Two in the experimental group were drawn from the same population. In other words, there is no significant difference between the scores in the two tasks for the 


\section{TABLE I}

\section{COMPOSITE OF INDIVIDUAL SCORES ON ALL TASKS}

A11. scores reported in this table are in the form of a percentage articulation errors per total number of syliables articulated. Experimental Subjects

\begin{tabular}{|c|c|c|c|c|}
\hline \multicolumn{2}{|l|}{$\begin{array}{l}\text { Subject } \\
\text { slumber }\end{array}$} & Task \#1* & Task \#2* & Task \#3* \\
\hline \multicolumn{2}{|c|}{$\begin{array}{l}1 \\
2 \\
3 \\
4 \\
5 \\
6\end{array}$} & $\begin{array}{l}17.81 \\
16.04 \\
18.52 \\
12.02 \\
11.43 \\
16.00\end{array}$ & $\begin{array}{r}21.54 \\
16.92 \\
8.67 \\
20.77 \\
19.64 \\
9.09\end{array}$ & $\begin{array}{r}19.23 \\
13.85 \\
6.00 \\
22.30 \\
17.26 \\
9.09\end{array}$ \\
\hline \multirow[b]{2}{*}{$\because$} & $\overline{\mathrm{X}}$ & 15.3033 & 16.1050 & 14.6217 \\
\hline & $s_{d}$ & 2.95 & 5.8129 & 6.2077 \\
\hline
\end{tabular}

Control Subjects

\begin{tabular}{|c|c|c|c|c|}
\hline \multicolumn{2}{|c|}{$\begin{array}{l}\text { Subject } \\
\text { Number }\end{array}$} & Task \#1* & Task $\# 2 *$ & Task \#3* \\
\hline \multicolumn{2}{|c|}{$\begin{array}{r}7 \\
8 \\
9(\sin 1) \\
10 \\
11 \\
12\end{array}$} & $\begin{array}{l}6.37 \\
7.06 \\
4.50 \\
6.40 \\
5.16 \\
6.25\end{array}$ & $\begin{array}{l}7.69 \\
3.08 \\
2.31 \\
5.38 \\
5.38 \\
2.31\end{array}$ & $\begin{array}{r}18.46 \\
7.69 \\
2.31 \\
9.23 \\
5.38 \\
1.54\end{array}$ \\
\hline \multirow{2}{*}{. } & $\overline{\bar{x}}$ & 5.4566 & 4.3583 & 7.4350 \\
\hline & $S_{d}$ & 1.0302 & 2.1546 & 6.1566 \\
\hline
\end{tabular}

* Task \#1 is the Spontaneous Speaking Task Task \#2 is the Oral Reading At Normal Rate Task Task \#3 is the Oral Reading At Fast Rate Task 
TABLE II

THE P-VALUES FOR THE EXPERIMENTAL GROUP

AND CONTROL GROUP COMPARING TASKS

$\therefore$ PERFORMED BY FACH GROUP

\begin{tabular}{|l|l|c|}
\hline \multicolumn{1}{|c|}{ Tasks Compared } & $\begin{array}{l}\text { Experimental. } \\
\text { Group }\end{array}$ & $\begin{array}{c}\text { Control } \\
\text { Group }\end{array}$ \\
\hline $\begin{array}{l}\text { Comparison of articulation error } \\
\text { rates in spontaneous speaking } \\
\text { task and oral reading at normal } \\
\text { rate task }\end{array}$ & .197 & .197 \\
$\begin{array}{l}\text { Comparisun of articulation error } \\
\text { rates in oral reading at normal } \\
\text { rate task and oral reading at } \\
\text { fast rate task }\end{array}$ & .380 & .268 \\
\hline
\end{tabular}

Note: .05 is the level of significance arbitrarily chosen for this study. 
experimental group.

Since the p-value for Task \#One and Task \#Two in the control group was also .197, the same conclusion can be drawn, there is no sienificant difference between the scores obtained in either task for the control eroup.

Comparison Two: Oral Reading at Normal Rate lask to Oral Reading at Fast Rate Task.

Table II reveals the p-values which were determined from comparing the scores in Task \#Two and Task \#Three, for both the experimental and control groups.

In Comparison Two, the p-value derived for the experimental group was .380 . This p-value indicates that repeating the two tasks would produce an approximately one out of three chance that the same scores also would be repeated. The .380 is much larger than the .05 level of significance set in this investigation. Therefore, it can be concluded that no signiflcant difference exists between the scores of the experimental group for Tasks \#Two and \#Three.

The p-value reached by comparing the scores in Task \#Two and Task \#Three for the control group was .268. As in the case of the experinental group, this is too large a p-value when compared to the .05 level of significance set for this study. Therefore, there is no significant difference between the scores in Task \#To and \#Three for the control group. 
Comparison Three: Control Group to Experimental Group on All Three Tasks

A third comparison was conducted to answer the question: DAd the experimental croup make signiflcantly more exrors on ail three tasks than the control group?

To answer this question a lann Whitney-U Test was performed between the two groups (experimental and control) for each of the three tasis. The resulting p-values are listed in Table III. The .050 level of significance was maintained, once again, for these tests. As can be noted in Table III, the p-values in all three comparisons is below the .050 level of significance. Therefore, it can be assumed there was a significant difference between the art1culation exror rates of the experimental and the control groups. Referring to Table I, it can be noted the individual articulation error rates of the experimental group subjects were numerically higher than those of the control group. Combining the results of the Mann Whitney-y Test and the numerically higher scores for the experimental group revealed in Table I, provide an answer to the question posed in the preceding paragraph. The experimental group did make significantly more articulation errors on all three tasks than did the control group.

\section{Discussion of Results}

As Slegel (1956, p. 7) states: "The null hypothes is is a hypothesis of no differences. It is usually formulated for the express purpose of being rejected . . ." Two null hypotheses were formulated in this investigation in an attempt to empirically support the use of reading materials in a treatment approach to the disorder known as 
TABLE III

THE p-VALUES FOR EACH TASK COMPARING THE

CONTROL AND EXPERIMENTAL GROUPS'

ARTICULATION ERROR RATE

Spontaneous Speaking Task

.001

Oral Reading at Normal Rate Task

.001

Oral Reading at Fast Rate Task

.047

Wote: .05 is the level of significance arbitrarily chosen for this study 
developmental apraxia of speech. Additionally, a possible treatment procedure was offered to improve articulation performance in children with DAS. This procedure was to have the children read aloud as fast as possible. The acceptance of these two null hypotheses negates the support for the above offered treatment procedure or the more general use of the written stimulus materials in treatment of DAS in children. The results of this study in terms of the Iiterature previously cited in Chapter II will be discussed individually in this section.

The present investigation's research design was patterned after the one in the Johns and Darley (1970) study. The results of the present investigation which was conducted with children who have DAS do not support, however, the results of the Johns and Darley study which was conducted with adult subjects who had an AAS. A direct comparison of the two studies is impossible, however, several factors can be hypothesized as possible reasons for the differing results including: differing age of the groups; differing reading abllities; conconnitant symbolfc language problems (in the Johns and Darley subjects); and tcst artifacts due to slightly different testing procedures.

Martin (1974), as noted in Chapter II, has stated that persons with apraxia of speech make more articulation errors on oral reading tasks than on spontaneous speech tasks as proof of a linguistic component of apraxia of speech. The acceptance of the first null hypothesis of the present study does not support his contention. The results of the present investigation, however, do not tend to support Rosenbek et al. (1974) either, as he stated that children with DAS 
will frequently perform better in oral reading than in speaking situations. The accoptance of the first null hypothesis of this study does not appear to support any of the sources from the 11terature cited in Chapter II. This acceptance appears to mean that for the six children dlagnosed as having a developmental apraxia of speech, in this study, the mode of articulatory performance, whether spontaneous speaking or reading, made no difference in their performance. Morley, (1965), Rosenthal (1971), Rosenbek and Wertz (1972), and Rosenbek et al. (1974) have all reported the usefulness and merit of using reading stimuli to improve articulation accuracy in children wth DAS; however, not one of these authors has cited empirical evidence justifying this treatment approach. In view of the present Investigation's fallure to support the above contention by these authors, this investigator offers an alternative hypothes is that something inherent in the structure of the reading situation, rather than the Idea of visual stimulation itself, may account for the apparent success of this type of treatment approach. That is to say, it may be something in the way the above authors presented the reading stimulus rather than the reading stimulus itself that accounted for the success of this approach. Perhaps the reading materials provided an external rate control or "metronome effect" for these chlldren. Yoss and Darley (1974) and Rosenbek et al. (1974) favor the use of slowing the rate of articulation in treatment of this disorder. As previously. noted in Chapter II, prosodic elements also are often disturbed in children with DAS. This, however, remains an untested hypothesis offered by this investigator, and much further study would be needed 
to verify $1 \mathrm{t}$

The aforementioned hypothesis does not account for the acceptance of the second null hypothes is of this study. Children with DAS did not make significantly more errors when asked to read as fast as possible, compared to reading at their normal rates. This result does not appear to agree with use of slowing the articulation rate and the use of the "judicious pause" suggested by Yoss and Darley (1974) and Rosenbek et al. (1974). It must be noted, however, that a slowed rate of articulatory performance was not part of the present investigation, and, therefore, cannot be directly compared to the tasks which were involved in this study. In other words, the affect of decreasing the articulation rate was not tested.

A discussion of results of this study always must be made in the ilght of the limitations of the study. The remainder of this section w1Il be devoted to describing the limitations and influencing factors of the present study.

The first and most obvious limitation to this study is the small sample size. Considerable difficulty was encountered in obtaining a sufficiently large sample of children in the experimental group. This difficulty, for the most part, was the result of the high proportion of children diagnosed as having DAS who also had other concommitant problems, such as: dysarthria; hearing loss; visual impairment; and/or receptive language delay. These subjects had to be excluded from the experimental group for the present investigation; therefore, because of the limited sample size, no generalizations to the entire population of children diagnosed as having a DAS can be made with confidence 
from the results of this study.

A second Iimiting factor to be considered is the effect of subject selection. As previously explained, great difficulty was encountered in obtaining a sample large enough to carry out this experiment. Additionally, the aim of this discriminating search for subjects was to obtain a population of subject's free from concommitant and, thus, possibiy contaminating problems. This screening of concommitant problems, however, prevents direct comparison with most of the studies which have appeared in the literature, because most of the studies (Rosenbek; et al. 1973; Wertz et al. 1970; and Rosenbek and Wertz 1971) have not screened their subjects for concommitant problems. Even the Johns and Darley (1970) study, a model for this study, used adult "aphasics" with AAS for their subjects. The possible effects of the concommitant problems noted in subjects from the studies mentioned above cannot be predicted at this time.

A third limiting factor of this study is the varying degree of severity of DAS in the children of the experimental group. This variance was noted in Table $I$, in the relatively large standard deviation scores $\left(S_{d}\right)$ derived for the experimental group on all three tasks. The affect of this varying degree of severity is to weaken any statement made about "an average subject" in the experimental group.

A fourth limiting factor of this study was the school age level of all the subjects. All subjects in the study had been in school at least three years. Additionally, all experimental subjects had received at least one year of speech treatment for articulation problems through their respective school systems. In addition to school 
speech treatment for the experimental subjects, all subjects in the study read at a 2.5 grade level or better as measured by the Range Achievement Test For Reading. liot all the children, however, had achleved that reading proficlency in the same manner. Some of the subjects had apparentiy learned to read via the "phonic" method while others had learned via the "sight" or "configuration" method. The affect, if any, of this difference in acquisition of reading skilis cannot be predicted at this time. It is of interest to note that every one of the experimental subjects, when asked to pick their worst subject in school, selected reading. None of the children in the control group selected reading when asked to pick their worst subject.

A final factor to be considered in this section is the administration of the oral reading at fast rate task. The instructions to each child for this task were: "Please read these paragraphs as fast as possible." : In reality, an informal assessment (by timing the tape recorded readings) revealed that for some of the subjects in the experimental group, there did not appear to be an increase in the actual reading speed. An increase in the reading speed would have revealed itseif in a shorter elapsed reading time for this task compared with the elapsed time of the reading at the normal rate task. It appeared, however, that the subjects visibly increased their tension, and appeared to articulate strings of the syllables faster than in reading at the normal rate task. These subjects increased the length of appropriate and inappropriate pauses in reading at the fast rate task which might account for this inconsistency. 
CHAPTER V

SUMMARY AND IMPLICATIONS

\section{Summary}

RecentIy; a number of treatment approaches for the disorder of developmental apraxia of speech in children have appeared in the 11terature. These treatment approaches make use of the visual modal1ty, and specifically use reading stimulus materials to improve articulation skills: These treatment procedures are subject, of course, to appropriate age and reading ability. Several authors have endorsed this use of reading materials in the treatment of DAS in children Including: Morley (1965); Rosenthal (1971); Rosenbek and Wertz (1972); and Rosenbek et al: (1974). These treatment approaches have been offered via the ilterature without the benefit of empirical verification that children with DAS will make fewer articulation errors while reading aloud than they would speaking spontaneously.

The primary purpose of this investigation was to provide empirical support for the treatment approaches to DAS in children which make use of reading stimuli to improve the articulation performance of these children. A secondary purpose was to present a possible treatment approach through the increasing of oral reading speed in children. with DAS. Tro specific null hypotheses were posed in this study:

1. ChIldren diagnosed as having developmental apraxia of speech will not make significantly more articulation errors on an oral reading task than they do on a spontaneous speaking task. 
2. Children diagnosed as having a developmental apraxia of speech will not make significantly more articulation errors on an oral reading task when reading at their normal rate, than when instructed to perform that oral, reading task as fast as possible.

Six children with DAS were chosen from the files of the Crippled Children's Division, University of Oregon Health Sciences Center. Those children were screened for concomitant visual problems, hearing problems, organlc disabilities, and symbolic language disab1lit1es. Six children from the Canby Public Schools, Canby, Oregon, all having normal articulation skills, served as the control group. Each subject was instructed to read several paragraphs aloud at his/her normal rate. Then the subject: was instructed to describe in his/her own words, several pictures. Finally, the subject was instructed to read the same paragraphs over; this time as fast as possible. Comparisons of the scores for the spontaneous speaking task and the oral reading at normal rale task were made in addition to comparisons between the scores for the oral reading at normal rate task and the reading at fast rate task. Analysis of the data via the Mann Whitney-U Test produced the following results:

1. Wo significant difference was found in the articulation error rates of the spontaneous speaking task and the oral reading at normal rate task, for elther the experimental or the control group.

2. No significant difference was found in the articulation error rates of the oral reading at normal rate task and the oral reading at fast rate task, for either the experimental group or the control group.

In conclusion, results of the present investigation do not tend to support the current treatment approaches appearing in the Iiterature which make use of reading stimulus materials to improve articulation 
skills of children with DAS. The results also do not support the possible treatment procedure offered involving increasing the oral reading speed to demonstrate improved articulation performance. The conclusions reached by this investigation must be tempered by the small sample size used in this study.

\section{Implications}

There are two specific implications which are offered for further study. This does not cover all the questions raised in this invest1gation; however, it does include the most obvious implications.

The most striking limitation of this study, namely the small sample size, is also the most obvious implication. That implication is : there is a need for cross validation and verification of the results of the present investigation using a larger sample size. Sheehan (1970) Indicates cross validation and veriflcation of moderate slze samples may be preferred to execution of one study with a large sample size.

The other Implication to be mentioned here is the need for further research to define the extent of disorder in DAS. This lack of clear definition is apparent in the area of reading. There is no empirical verification that the reading errors made by children with DAS are the same type of errors made by children with normal articulation skills nor has the contention by Rosenbek et al. (1974) that placing system of written prosody cues over reading materials, w1Il improve articulatory performance of children with DAS. The lack of definition also is apparent in the high proportion of children with 
DAS who also have other concomitant problems.

To conclude, this study has raised more questions than it has answered. These questions are among those which must be answered before systematic, precise treatment programs can be developed to effectively aid children with developmental apraxia of speech. 
B I B L I O G A PHY 


\section{BIBLIOGRAFHY}

A'l's', I., Johns, F., and Darley, F. I. Auditory Perception of Sequenced Words in Apraxia of Speech. J. Speech Hearing Dis., 14, 131-143, $(1971)$.

EriuNING, J. I., and Kintz, B. I., Computational Handbook of Statistics. New York: Scott Foresman and Co. (1968).

CHAPPELI, G. E., Childhood Verbal Apraxia and its Treatment. J. Speech Hearing Dis. 38, 362-368 (1973).

DABUL, B. I., Iingual Inco-Ordination-Language Delay. California Journal of Communicative Disorders, 2, 30-33 (Fal1-1971).

DALY, D. A., Cantrell, R. F., Cantrell, M. L., and Altman, A., Structuring Speech Therapy Contingencies With an Oral Apraxic Child. J. Speech Hearing Dis., 37, 22-37 (1974).

DARLEY, F. L., Apraxia of Speech 107 Years of Terminological Confusion. Paper presented at American Speech and Hearing Association Convention, Denver, (November, 1968).

DARLEY, F.. I., Apraxia of Speech, Description, Diagnosis, and Treatment. A dual session presentation at the American Speech and Hearing Association Convention, New York City, (November, 1970).

DEAL, J. L., The Influence of Iinguistic and Situational Variables on Phonemic Accuracy in Apraxia of Speech. A paper presented at American Speech and Hearing Association Convention, New York City, (November, 1970).

DUNN, L. M., Peabody Language Kit - Level 1. Circle Pines, Minnesota: American Guidance Service Inc. (1965).

DUNN, I. M., Peabody Plcture Vocabulary Test. Circle Pines, Minnesota: American Guldance Service Inc. (1965).

EDWARDS, M., Developmental Verbal Dyspraxia. Brit. J. Dis. Commun., $64-70$ (1973).

FAY, W. Lecture: Developmental Verbal Apraxia. Presented at Portland State University, (1974).

FERRY, P. C., HaII, S. M., and Hicks, J. L., Verbal Dyspraxia in Children: A Neurological Cause of Foor Speech. Journal of the Oregon Speech and Hearing Association, 31, 14-19 (1974). 
GESCHWIND, N., The Apraxias: Neural Mechanisms of Disorders of Learned Movement. American Scientist, 63, 188-195 (March-April, 1975).

JOHNS, D. L. and Darley, F. L., Phonemic Variability in Apraxia of Speech. I. Speech Hearing Res., 13, 555-582 (1970).

JUSTAK, J. F., Bi jou, S. W., and Justak, S, R., Wide Range Achievement Test for Reading. Wilmington, Delaware: Guldance Associates of Delaware, Inc. (1965).

LAPOINTE, L. L., Phonemic Characteristics in Apraxia of Speech which Aid in Differentiating Among Articulation Disorders in Brain Injured Adults. A paper presented at the American Speech and Hearing Association Convention, New York, (November, 1970).

MARTIN, D. A., Some Objections to the Term Apraxia of Speech. J. Speech Hearing Dis., 39, 53-64 (1974).

MORLEX, $H_{*}$, Development and Disorders of Speech in Childhood, (2nd ed.). Baltimore, Maryland: Williams and Wilkins Co. (1965).

MORLEY, $H_{0}$, and Fox, J., Disorders of Articulation: Theory and Therapy. Brit. J. Dis. Commun., 4, 151-165 (1969).

ORTON, S. T., Reading, Writing, and Speech Problems in Children. New Yorks W. W. Norton Co. Inc., (1937).

PAIMER, M. F., Wurth, C. W. and Kincheloe, K. W., The Incidence of Lingual Apraxiá and Agnosia in Functional Disorders of Articulation. Cerebral Palsy Review, 25, 7-9 (Nov.-Dec., 1964).

PENDERGAST, K., Photo Articulation Test. Chicago: The King Co. (1965).

ROSENBEK, J. C., and Wertz, R. T., A Review of 50 Cases of Developmental Apraxia of Speech. A paper presented at the Colorado Speech and Hearing Association Convention, (May, 1971).

ROSENBEK, J. C., and Wertz, R. T., Treatment of Apraxia of Speech In Adults. A paper presented at the Second Conference of Clinical Aphasiology, New Mexico, (Narch, 1972).

ROSENBEK, J. C., Wertz, R. T., and Darley, F. I., Oral Sensation and Perception in Apraxia of Speech and Aphasia. J. Speech Hearing Res., 16, 22-36 (1973).

ROSENBEK, J. C., Hansen, R., Baughman, C. H., and Lemme, M., Treatment of Developmental Apraxia of Speechs A Case Study. Language, Speech, and Hearing Services in the Schools, 13-22 (1974). 
ROSENTHAL, J., A Token Reinforcement Programme Used in the Treatment of Articulatory Dyspraxia in a Nine-Year Old Boy. J. Australian College of Speech Therapists, 21, 45-48 (1971).

SHANKWELLER, D., and Harris, K. S., An Experimental Approach to the Problem of Articulation in Aphasia. Cortex, II, 277-292 (1966).

SHEEHAN, J. G., Stuttering: Research and Therapy. New Yorks Harper \& Row, $(1970)$.

SIEGEL, S., Nonparametric Statistics For The Behavioral Sciences. New York: McGraw-Hill Book Co. (1956).

TABER, C. W., Taber's Cyclopedic Medical Dictionary. Philadelphias F. A. Davis Co. (1970).

WERTZ, R. T., Rosenbek, J. C., and Deal, J. I., A Review of 228 Cases of Apraxia of Speech Classification, Etiology, and Iocalization. A paper presented at the American Speech and Hearing Association Convention, New York, (Nov., 1970).

WINITZ, H., Articulatory Acquisition and Behavior. New York: AppletonCentury-Crofts, (1969).

YOSS, K. A., Developmental Apraxia of Speech in Children with Defective Articulation. Unpublished dissertation, Florida State University, (1972).

Yoss, K. A., Developmental Apraxia of Speech in Children with Defective Articulation. A paper presented at the American Speech and Hearing Association Convention, San Francisco, (1972).

YOSS, K. A., What Happens to Children With Developmental Apraxia of Speech? A Follow-Up of Fifteen Cases. A paper presented to the American Speech and Hearing Association Convention, Detroit, (1973).

YosS, K. A., and Darley, F. L., Therapy in Developmental Apraxia of Speech. Language, Speech, and Hearing Services in the Schools, 5. 23-31 (1974). 
A P E NDICES 
APPENDIX A

\section{BEHAVIORAL CHARACTERISTICS OF \\ APRAXIC-IIKE SPEECH}

From Darley, Frederick L. "Apraxia of Speech: 107 Years of Terminological Confusion." American Speech and Hearting Association Convention, Denver, November, 1968.

Characteristic "Behavioral Strands" of Apraxia of Speech. (Although

a developmental analog of this disorder has been recognized, this

Iisting is based upon reports of acquired conditions).

1. There is an absence of significant weakness, paralysis, and incoordination of the speech apparatus. We do not mean to say that all patients will be without some weakness, but the weakness that is seen is inadequate to explain the articulatory problems that appear.

2. There is a discrepancy between speaking performance and performance in the other language modalities. We do not assert that these patients may not demonstrate some impairment of comprehension, some genuine Iinguistic impairment, but as their performance in the various modalities is carefully evaluated, their speaking performance usually appears to be worse than their performance in listening, reading, or writing. The point is that the articulatory problem is not an integral part of the aphasia.

3. The most prominent feature of the problem is the existence of phonemic errors: omissions, substitutions, and distor- 
tions of all kinds. Some of these errors appear to be perseverative, ot hers anticipatory.

4. The patient gropes for the right position of his articulators, producing approximations to the sound, being repeatedIy off-target. His groping to produce individual sounds and sequences of sounds is obviously effortful.

5. Errors are inconsistent. As the speaker is repeatedly off-target in his approximations, he is off-target in varlous ways. He may substitute first one sound, then another; he may omit the sound; he may repeat it; he may slight it or distort; ultimately he may produce it correctly, only to misarticulate it immediately after.

6. The patient poorly imitates a single auditory stimulus which he receives. Speech produced in repetition of what another speaker says is often very poor.

7. There is variation in the correctness of articulation depending upon the complexity of positioning required for given speech sounds. A bilablal sound may be usually correct, whereas a sound more hidden or involving a nicer adjustment of the musculature may be often misarticulated. Consonant clusters appear harder than single consonants.

8. Errors vary with the length of the unit that the speaker is trying to produce. He may do quite well on monosyllables, less well on two-syllable words, and increasingly poorly on increasingly long poly-syllabic words.

9. There 1s evident discrepancy between certain speech perform- 
ances and others. Just as in a nonlanguage apraxia, we find a discrepancy here between volitional performance and reflex performance. We may hear a patient comment upon his poor performance in saying certain words after us, and as he comments he is fairly fluent and his articulation is fairly good. He may be able to recite numbers or days of the week and produce such reactive expressions as greetings or curses fluently and with good articulation, but when his set is different in trying to produce a particular word, even though It is an easy one, he may have much trouble.

10. The patient is often aware of his error but is frequently unable to correct $1 t$.

11. The prosody of speech is disturbed. Especlally patients who have learned to cope with the problem over a perlod of months w11l seem to be tip-toeing through speech, unsure as to how each phoneme is to be produced, approaching each sound warily, deliberately placing the articulators, often exaggerating the consonants. The result. is a slowex than usual rate with rather even stress and even spacing of syllables and words.

12. Some patients experiencing severe difficulty intitiating words produce repetitious, dysfluent speech which sounds much like stuttering.

13. Some patients but not all display an assoclated oral apraxia. These distinctive characteristics warrant the adoption of terminology which differentiates this disorder clearly 
from problems due to muscular weakness or incoordination, which we shall call dysarthria; and from problems due to inefficlent processing of linguistic units, which we shall call aphasia. A separate term--apraxia of speech--best denotes the dynamics of the problem and obviates the necess1ty for an intervening step of redescription often resorted to when terms like "cortical dysarthria" or "motor aphasia" are used. This term also suggests the therapeutic approach most efficacious: direct drill on speech sounds using phonetic placement and providing through the mirror or other techniques abundant visual and tactile cues rather than the general language stimulation effective in aphasia. We suggest this three-fold terminology! dysarthria, aphasia, and apraxia. If we apply unclear or overlapping labels and let our language do our thinking for us, we may end up misunderstanding the disorder of apraxia of speech and mistreating the patient who is handicapped by it. 


\begin{abstract}
APPENDIX B
CHARACTERISTICS OF DEVELOPMENTAL APRAXIA OF SPEECH
\end{abstract}

May occur in isolation or in combination with aphasia and/or dysarthria.

Speech development is delayed and deviant.

Receptive abilities are inordinately superior to expressive abilities.

Oral, non-verbal apraxia often, but not always, accompanies apraxia of speech.

Prominent phonemic errors: omissions*, substitutions, distortions, additions, repetitions, prolongations.

* Frrors are more often omission of sounds and syllables than substitution of sounds and syllables.

Frequent metathetic errors.

Exrors increase as words increase in length.

Repetition of sounds in isolation is often adequate: connected speech is more unintelligible than would be expected on the basis of single word articulation test results.

Exrors vary with the complexity of articulatory adjustments most frequent errors are on fricatives, affricatives, and consonant clusters. Misarticulations include vowels as well as consonants. Errors are highiy inconsistent.

Prosodic disturbances: slowed rate, even stress, and even spacing perhaps in compensation for the problem. 
Groplng trial-and-error behavior: manifested as sound prolongations, repetitions, or silent posturing which may precede or interrupt imitative utterances.

Rosenbek and Wertz, 1971 
DEVELOPMENTAL VERBAL DYSPRAXIA

\section{Characteristics}

1. There is an absence of signiflcant weakness, paralysis and Incoordination of the speech apparatus.

2. Speech development is delayed and deviant.

3. May be accompanied by oral apraxia and/or $11 \mathrm{mb}$ apraxia.

4. Oral diadochokinesis is typically slow, labored, disordered, or seemingly impossible for two or more syllables.

5. May occur in isolation or with other disabilities (e.g., dysarthria, aphasia, mental retardation).

6. Verbal reception is typically far better than expression.

7. Child may present a history including sucking, chewing, swallowing problems; dressing confusion.

8. Phonemic errors include cognate volcing mistakes, omissions, substitutions, distortions, additions, repetitions, prolongations.

9. Vowels may be involved to a lesser extent; diphthongs are nore commonly faulty.

10. Metathesis (phonemic transposition) are common ("zone" for "nose," "kahy" for "hockey," and "mulcks" for "music").

11. Errors are highly inconsistent varying with the complexity of articulatory adjustment; most frequent errors are on frlcat1ves, affricatives, and consonant clusters.

12. Errors increase as the utterance increases (syliables-words--phrases--sentences $)_{i}$ isolated phonemic production is often adequate. 
13. In repeating short 1 ists of words, memory failures, reordering, and circumlocutions (substituting semantic equivalents) are comnon.

14. The speaker is often aware of his error, but is frequently unable to correct it.

15. The prosody of speech (melody, rate, stress, spacing) may be involved as a secondary consequence of the speech effort.

16. As the child grows older, productions are likely to be closer to the target and thus more easily assessed.

17. Groping trial-and-error behavior is almost universal. Prolongations, repetitions, circumlocutions and silent posturing of the articulators characterize imitative utterances. 


\section{APPENDIX C \\ IIST OF DESCRIPTIVE DIAGNOSTIC \\ STATEMENTS RANK ORDERED BY \\ THREE SPEECH PATHOLOGISTS}

Rank Order

* 1. General volitional control problems for the oral structures and/or slow diadochokinetic rate.

* 2. The more syllables per utterance, the greater the chance of articulation error. Also, more articulation errors in polysyllabic words.

3. Immature or deviant use of syntactical structures such as: incorrect verb usage; incorrect pluralization; inappropriate pronoun usage; omission of words (articles, prepositions, and/or modifiers); omission of word endings.

* 4. Verbal language expression skills are delayed or deviant.

* 5. Verbal sequencing skills sln or deviant, particularly in repetition of 3-syllable phrases such as puh-tuh-kuh.

6. Poor speech intelligibility ( $50 \%$ or less).

7. Multiple articulation errors in consonants includings omissions, substitutions, and distortions.

8. Inconsistency in articulation pattern - including articulation error pattern.

9. Verbal language comprehension skills are within normal limits.

10. Telegraphic speech pattern.

11. Write in additional descriptors here if necessary. Please indicate rank of these additional descriptors.

*One of top five diagnostic statements picked 


\section{APPENDIX D}

\section{ORAI READING TASK}

A long time ago a little red hen lived alone in a big forest. She lived in a fine home. It was made of strong brick.

Inside her home, Iittle Red Hen had a stove, a chair, a table, and a small bed. There was a green quilt on the bed. Little Red Hen had made the quilt herself.

"This little home is fit for a queen," she said. Yes, she Iiked her home. It had a yard and a garden. She spent much of her time in the garden, spading, and seeding, and weeding it. Little Red Hen worked Inside her home, too, cleaning it and flxing things to eat. 


\section{APPENDIX E}

$$
\begin{aligned}
& \begin{array}{c}
\text { BASIC FORMULA FOR THE } \\
\text { MANN WHITNEY-U TEST }
\end{array} \\
& \text { or } \\
& \qquad=n_{1} n_{2}+\frac{n_{1}\left(n_{1}+1\right)}{2}-R_{1} \\
& \text { where } n_{1}=n_{1} n_{2}+\frac{n_{2}\left(n_{2}+1\right)}{2}-R_{2} \\
& n_{2}=\text { size of the smaller sample } \\
& R_{1}=\text { sum of the larger sample } \\
& R_{2}=\text { sum of the ranks of the larger sample }
\end{aligned}
$$

Siegel, 1956 
APPENDIX $F$

AGE, SEX, AND ASS IGNED NUMBER

FOR EACH SUBJECT

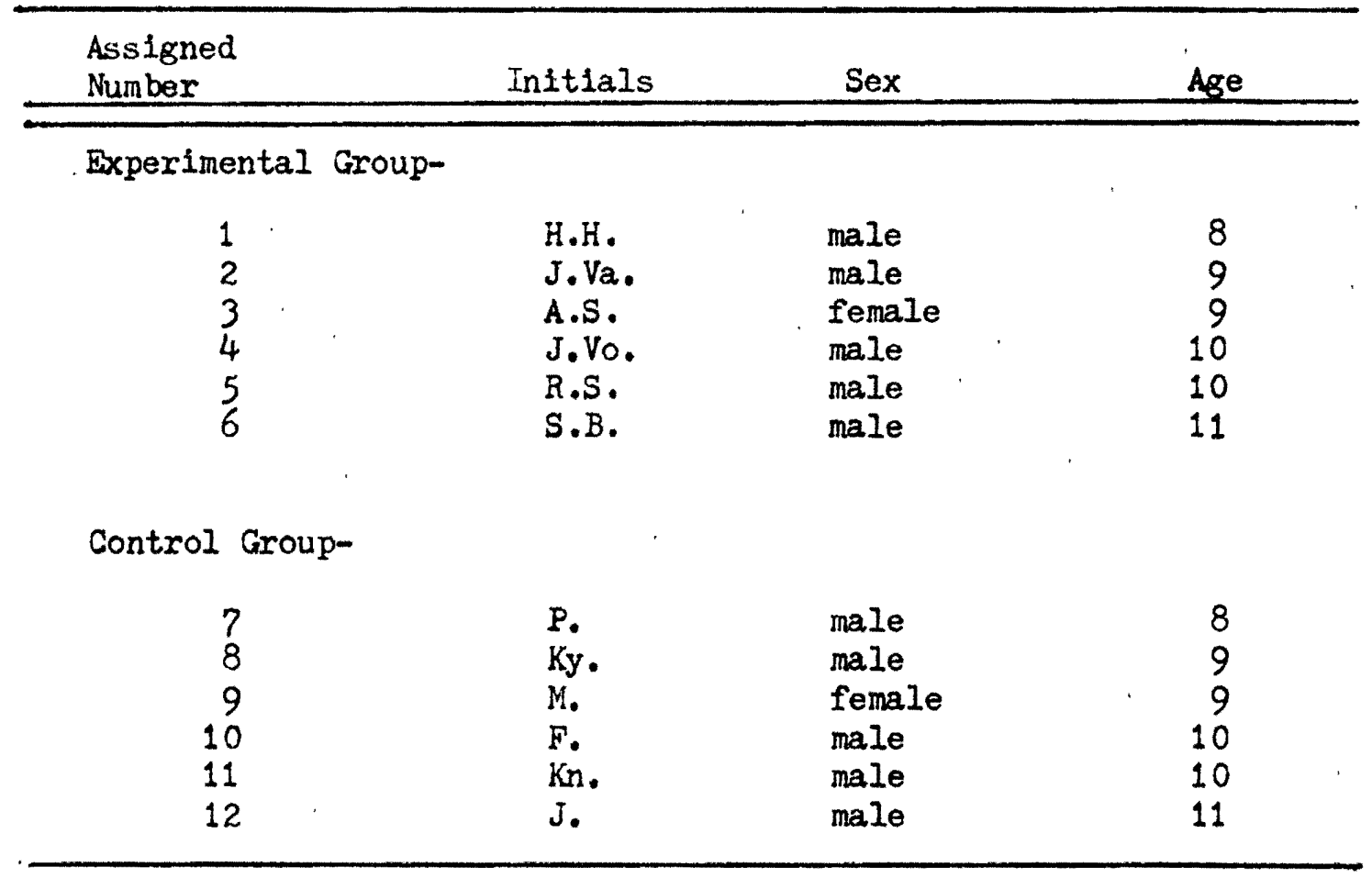

